\title{
Modeling of earth fissures caused by land subsidence due to groundwater withdrawal
}

\author{
B. B. Panda, M. L. Rucker, and K. C. Fergason \\ Amec Foster Wheeler, Phoenix, Arizona, USA \\ Correspondence to: B. B. Panda (bibhuti.panda@amecfw.com) \\ Published: 12 November 2015
}

\begin{abstract}
Land subsidence and earth fissures are phenomena related to groundwater withdrawal in a sedimentary basin. If the rock basement or basin lithology is irregular, both vertical and horizontal displacements can be induced due to differential settlement and tensile stresses appearing in the soil mass. If the differential settlement is of sufficient magnitude, earth fissuring can occur within tensile zones. The magnitudes of compaction and fissure geometry are closely related to the thickness and skeletal compressibility of fine-grained sediments within the aquifer system. Land subsidence and earth fissuring were modeled by employing a two-dimensional (2-D) coupled seepage and stress-strain finite element analysis. The basin bedrock geometry, lithological variation, measurements of surface displacements, and changes in hydraulic head were the critical input parameter for the subsidence modeling. Simulation results indicate that strain had exceeded the approximate threshold for fissure formation of 0.02 to $0.06 \%$ in the area of the identified fissures. The numerical model was used to predict future subsidence and potential earth fissures for flood control structures within the metro Phoenix area.
\end{abstract}

\section{Introduction}

Land subsidence due to groundwater withdrawal in alluvial basins in the southwest region of USA is a process of differential compaction of deep sediments. The effect of groundwater pumping on ground deformation in south central Arizona was investigated by many researchers (Boling et al., 1980). The application of interferometric synthetic aperture radar (InSAR) to characterize the distribution and rate of land subsidence provided invaluable detail into the probable positioning of tensile ground stresses and earth fissuring (AMEC, 2003). The differential rates and magnitudes of subsidence over relatively short distances, cause horizontal strains due to tensile stresses and eventually can become sufficient to cause earth fissuring. Jachens and Holzer (1982) concluded that most fissuring occurred at horizontal tensile strains in the range of 0.02 to $0.06 \%$. Numerical models have been developed by the authors (Panda, 2007; AMEC, 2003, 2013) to assimilate both InSAR and historic subsidence data for prediction of subsidence and earth fissure due to groundwater withdrawal.

\section{Theory}

The change in pore pressure in any soil layer due to withdrawal of water with time is related to the change in void ratio by the following equation:

$p=\frac{e}{a_{\mathrm{v}}}$

where $p=$ change in pore pressure, $e=$ change in void ratio, and $a_{\mathrm{v}}=$ coefficient of compressibility (related to skeletal compressibility).

The vertical settlement of any soil depends on the void ratio and thickness of the soil layer.

$s=e 2 H$

where $s=$ vertical settlement at time $t$ and $2 H=$ total vertical thickness of the medium.

The amount of compaction and fissure location are closely related to the thickness and skeletal compressibility of finegrained sediments within the aquifer system. 


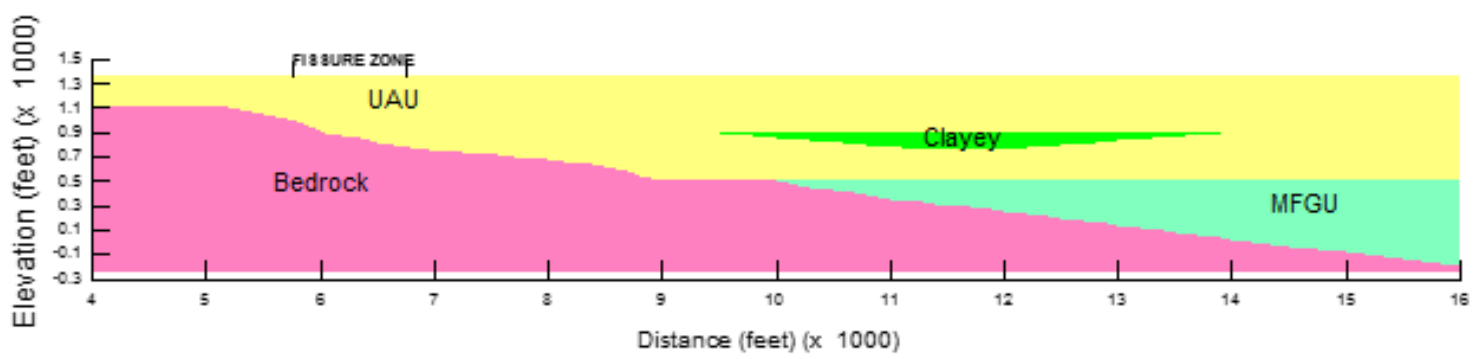

Figure 1. Finite Element Model Geometry along McMicken Dam.

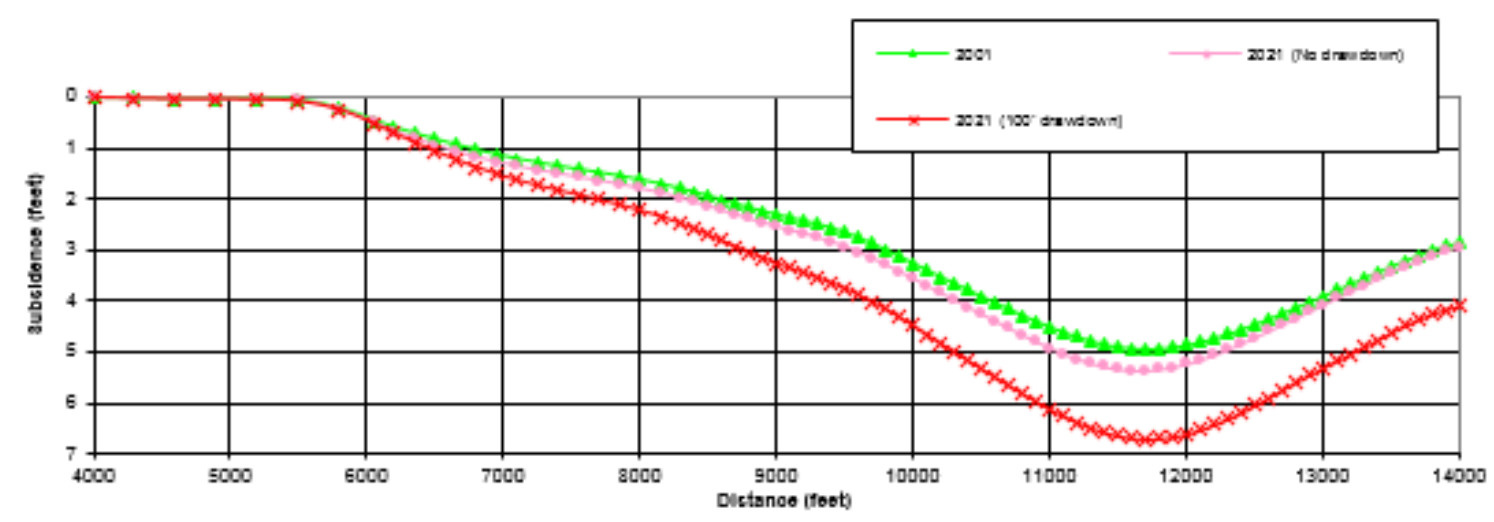

Figure 2. Prediction of vertical subsidence along the McMicken Dam.

\section{Modeling concepts}

A fully coupled analysis requires that both the stressdeformation and seepage dissipation equations be solved simultaneously. This coupling was achieved by using two finite element-based computer programs, SEEP/W and SIGMA/W (Geo-Slope, 2012). Modeling of the earth fissure for two dimensional (2-D) geometry is performed by calculating the tensile strain along the surface of any linear structure. The tensile strain is developed mainly due to differential settlement of the ground surface. Input data for the modeling effort consisted of an array of interrelated geometric and numerical components, including alluvial lithology, hydrological data and assigned mechanical properties of the alluvial materials. The numerical model was calibrated using InSAR and survey data. The input parameters for the 2-D models were estimated from the 1-D model based on percolation theory approach (AMEC, 2013).

\section{Case history}

\subsection{McMicken Dam, Phoenix, Arizona}

McMicken Dam is part of a system of flood retention and conveyance facilities that protect the metropolitan area of Phoenix, Arizona. The 9-mile long, earthen embankment of McMicken Dam was constructed in 1955 along the allu- vial flank of the White Tank Mountains. McMicken Dam has experienced over 5 feet of differential subsidence due to groundwater pumping in the deep basin sediments of the Phoenix aquifer (AMEC, 2003). The vertical subsidence along the dam profile is modeled using the finite element method. The conceptual model geometry used in finite element model along the dam is presented in Fig. 1. Two different future drawdown scenarios were assumed for subsidence prediction. In a first scenario, no drawdown was assumed for 20 years while 100 feet drawdown in 20 years was assumed for a second scenario. The predicted vertical subsidence along the dam profile is presented in Fig. 2. The modeled horizontal strain along the dam profile is presented in Fig. 3. The modeled horizontal strain in excess of the threshold $0.02 \%$ strain was estimated at the location of known earth fissures. The model also shows another two locations along the profiles, where the tensile strain is approaching or at the threshold value. These two locations may be regarded as zones with a greater potential for the development of earth fissure.

\subsection{Powerline floodway, Mesa, Arizona}

Subsidence and earth fissuring in the vicinity of Powerline floodway, has been investigated and numerical models were developed (AMEC, 2013) to predict future subsidence and earth fissure potential along the Powerline floodway. An 


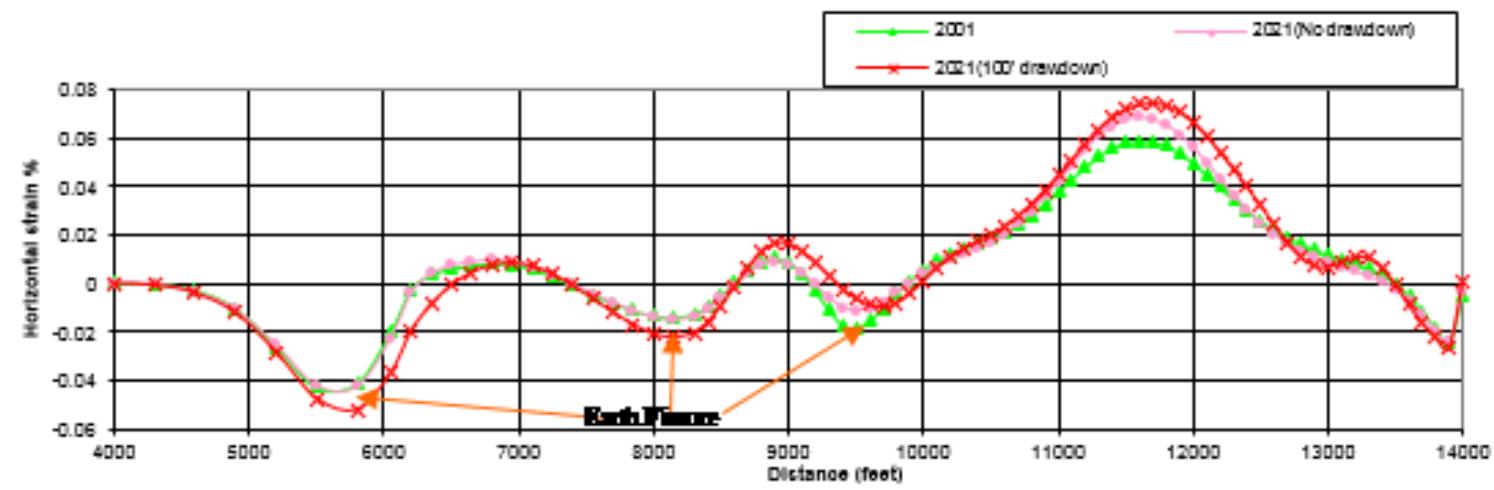

Figure 3. Prediction of horizontal strain and location of potential earth fissure zone along the McMicken Dam.

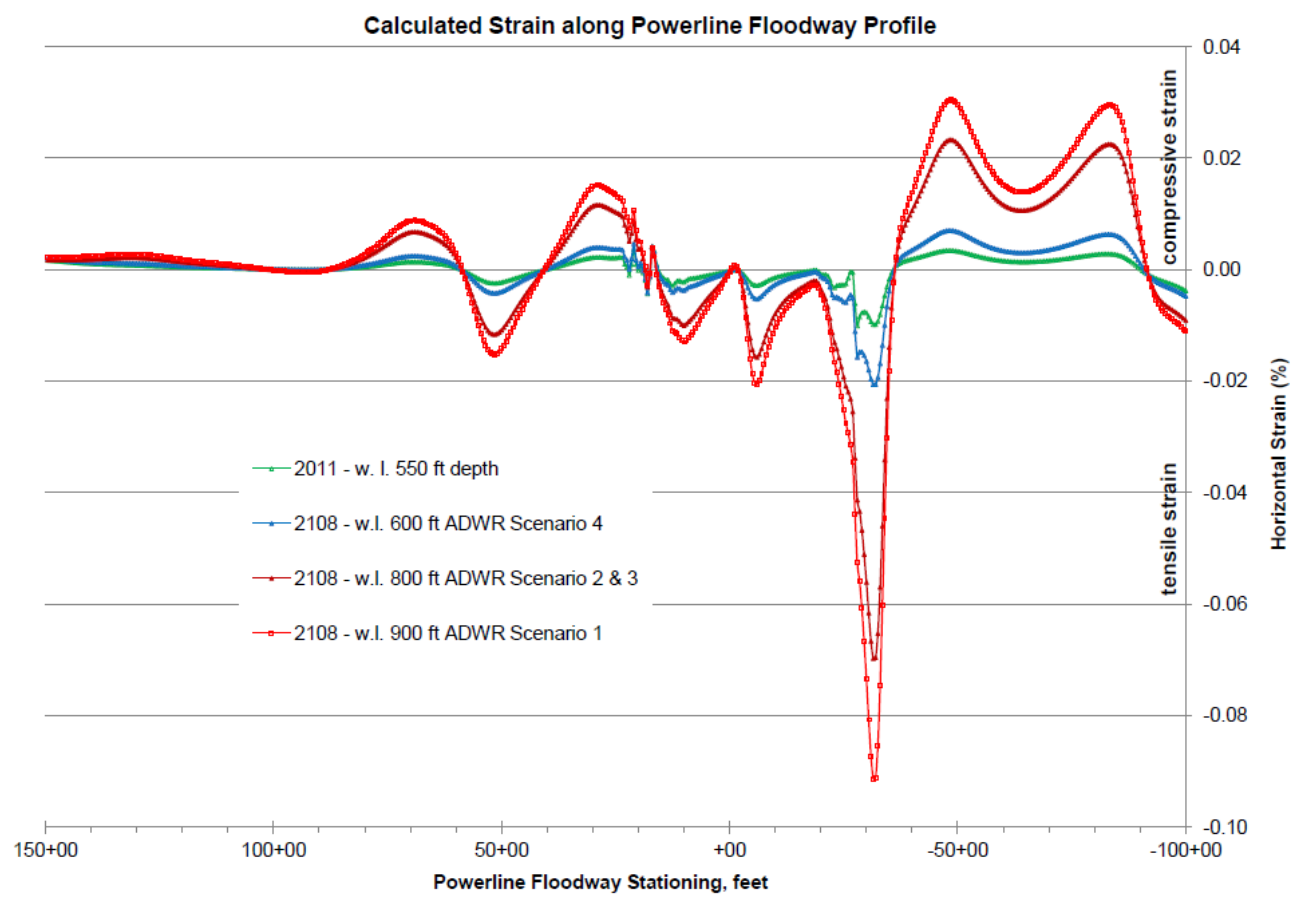

Figure 4. Prediction of horizontal strain along the Powerline floodway structures.

earth fissure observed along the dam was calibrated through numerical modeling (AMEC, 2013). The calibrated model was used to predict the future earthfissure potential along the floodway based on various ground water pumping scenarios. The estimated horizontal strain from the finite element model simulation along the powerline floodway is presented in Fig. 4. Although the simulated current ground strains have not reached the threshold limit of 0.02 , future strains under various groundwater pumping scenarios clearly shows the potentail for future development of earth fissures along the floodway.

\section{Conclusions and discussions}

The earth fissures resulting from ground subsidence due to the withdrawal of groundwater were modeled using coupled flow and deformation finite element models. The numerical model simulated the past ground subsidence and observed earth fissure activity along the flood control retention structures in Arizona. The numerical simulation demonstratted the strong influence of the depth of bedrock and the distribution of alluvial lithology on the subsidence and location of earth fissures. It is recommended that the ground subsidence and earth fissure activity due to future groundwater pumping in the area should be consindered in the design of flood control structures. The numerical model was used as a suitable tool to estimate future subsidence and earthf issure potential 
based on future groundwater pumping scenarios. The identification of potential earth fissure zones based on finite element horizontal strain estimation also assists in the planning of the earth fissure monitoring system for the structures.

\section{References}

AMEC Earth \& Environmental, Inc. (AMEC): Earth fissure investigation report, McMicken Dam, Work Assignment Nos. 4 \& 5, Contract FCD 2000C006, Maricopa County, 60 pp., 11 April 2003.

AMEC Environmental 7 Infrastructures, Inc. (AMEC): Final design level subsidence and earthfissure risk zoning report Powerline, Vineyard Road and Rittenhouse Flood retarding Structures, prepared for Flood Control District of Maricopa County Contract FCD 2011C005 Work Assignment No. 12, AMEC Job No. 172013-4045, 421 pp., December 2013.
Boling, J. K., Carpenter, M. C., Johnson, N. M., and Davis, S. N.: Measurements, prediction and hazard evaluation of earth Fissures and subsidence, South Central Arizona, OWRT Project No. A-092-Ariz, The University of Arizona, Tucson, 46 pp., 1980.

Geo-Slope International Ltd.: Finite element stress and deformation analysis, Computer Program SIGMA/W, Calgary, Alberta, Canada, 2012.

Jachens, R. C. and Holzer, T. L.: Differential Compaction mechanism for earth fissures near Casa Grande, Arizona, Geol. Soc. Am. Bull., 93, 998-1012, 1982.

Panda, B. B.: Prediction of Ground Deformation due to Groundwater Withdrawal using Numerical Simulations, Proceedings of First Sri Lankan Geotechnical society International conference on Soil and Rock engineering, Columb, 8 pp., 6-11 August 2007. 